\title{
DETERMINATION OF KEY SECTORS IN A REGIONAL ECONOMY THROUGH INPUT-OUTPUT ANALYSIS: COMMENT
}

William A. Schaffer*

The paper by Hayashi, Mullendore, and Ekholm offers an excellent survey of measures of interindustry linkages and correctly reports their inadequacy as means of identifying key sectors in an economy. My major objection to the paper is that it is too gentle in rejecting the key-sector approach to identifying industries on which to base regional development. 1

A serious fault of many input-output studies lies in the confusion created by an implied relation between analysis and policy. We identify key sectors through the described linkage measures or, more often, through a set of multipliers and imply that our analysis has yielded results of critical importance to policymakers.

In preparing both the Hawaii and the Georgia input-output studies, ${ }^{2}$ we computed measures of interindustry linkages but then decided not to pursue the question further. It just seemed absurd to tell state planners that the backward linkages among industries in Georgia a re highest in diary products, meat products, and canned foods and to advise that the se "key sectors" should be emphasized in planning economic development. These may well be key sectors in the state's economy, but they a re certainly not the keys to higher per capita incomes and the advice certainly would not enhance the reputation of the analyst!

In a similar vein, output and income multipliers are more analytical tools than they are policy tools. It does little good to point out that the income created per dollar of final sales in apparel is the highest for any industry in the state.

To overcome these weaknesses in the more traditional tools, we rely in Georgia on a "skyline chart" and anindex of per employee income change. By tracing direct and indirect exports andimports, the skyline chart assists us in pointing out "missing links" in the economy. The chart must be supplemented with, among other things, comparative-cost analyses which identify feasible changes in the economic structure of the state.

The per-employee-income index is the ratio of an income multiplier to an employment multiplier and proves a useful tool for discussing a vital aspect of economic development. Thus, it correctly identifies the apparel industry as being associated with low incomes per employee and the aircraft industry with high ones. It does not identify linkages but it translates the multiplier linkages into more useful expressions.

The linkage measures needed in regional studies are more than those associated with direct-requirements and inverse matrices. We should identify the links between industries in and out of the subject region which cause changes in trade patterns. The measures discussed here have been based on a static model of a relatively open economy. They relate to changes in output associated with changes in final demand; they do not identify changes in economic structure caused by changes in final demand or by the changes made to initiate unbalanced growth. Determination of key sectors with the traditional measures typical to most regional input-output studies remains an exercise of little consequence to policymakers.

*Associate Professor of Economics, Georgia Institute of Technology. 


\section{FOOTNOTES}

${ }^{1}$ A more violent critique and rejection of the key-sector approach appears in Krishna R. Bharadwaj, "A Note on Structural Interdependence and the Concept of 'Key" Sector", Kyklos, XIX (1966), 315-19.

2 These studies are documented in William A. Schaffer, Young Joun, and others, Interindustry Study of the Hawaiian Economy (Honolulu: Department of Planning and Economic Development, State of Hawaii, 1972), and William A. Schaffer, Eugene A. Laurent, and Ernest M. Sutter, Jr., Using the Georgia Economic Model (Atlanta: Office of Industrial Management, Georgia Institute of Technology, 1972) 